\title{
QUALIDADE DAS SEMENTES DE SOJA PRODUZIDAS SOB MANEJO COM BIORREGULADOR ${ }^{1}$
}

\author{
LEANDRO PAIOLA ALBRECHT²; ALESSANDRO DE LUCCA E BRACCINI²; \\ CARLOS ALBERTO SCAPIM²; MARIZANGELA RIZZATTI ÁVILA²; ALFREDO JUNIOR PAIOLA ALBRECHT; \\ MAURO CEZAR BARBOSA ${ }^{4}$.
}

\begin{abstract}
RESUMO: O objetivo do presente trabalho foi avaliar a qualidade fisiológica e sanitária das sementes, em resposta à aplicação do biorregulador Stimulate ${ }^{\circledR}$ na cultura da soja. Para tanto, sementes de soja da cultivar BRS 246 RR foram semeadas no mês de outubro dos anos agrícolas de 2007/2008 e 2008/2009, no delineamento experimental em blocos completos com os tratamentos casualizados, com quatro repetições. Os tratamentos, arranjados em esquema fatorial, foram compostos pela combinação do tratamento de sementes com o biorregulador (sem e com $0,500 \mathrm{~L}$ $100 \mathrm{~kg}^{-1}$ de sementes) e cinco doses do produto $\left(0 ; 0,125 ; 0,250 ; 0,375\right.$ e $\left.0,500 \mathrm{~L} \mathrm{ha}^{-1}\right)$ aplicadas via foliar, em dois estádios de desenvolvimento da cultura $\left(\mathrm{V}_{5}\right.$ ou $\left.\mathrm{R}_{3}\right)$. O uso do biorregulador Stimulate ${ }^{\circledR}$ altera positivamente qualidade das sementes, sobretudo quando as aplicações foliares ocorrem no estádio $\mathrm{V}_{5}$.
\end{abstract}

Termos para indexação: Glycine max, regulador vegetal, germinação, sanidade.

\section{SEED QUALITY OF SOYBEAN PRODUCED WITH BIOREGULATOR MANAGEMENT}

\begin{abstract}
The objective of this study was to evaluate the physiological and sanitary quality of soybean seeds treated with the growth regulator Stimulate ${ }^{\circledR}$. Seeds of the cultivar BRS 246 RR were planted in October of crop years 2007/2008 and 2008/2009, in a randomized complete block design with four replications. The treatments were set out in a factorial, with a combination of seed treatment and the growth regulator (with and without $0.500 \mathrm{~L} .100 \mathrm{~kg}^{-1}$ bean) at five product dosages $\left(0,0.125,0.250,0.375\right.$ and $\left.0.500 \mathrm{~L} \mathrm{ha}^{-1}\right)$ with foliar application at two developmental crop stages $\left(\mathrm{V}_{5}\right.$ or $\left.\mathrm{R}_{3}\right)$. The application of Stimulate ${ }^{\circledR}$ positively altered seed quality, especially at the $\mathrm{V}_{5}$ stage.
\end{abstract}

Index terms: Glycine max, plant growth regulator, seed germination, health.

\footnotetext{
${ }^{1}$ Submetido em 18/03/2010. Aceito para publicação em 07/07/2010. Parte integrante da Tese de Doutorado do primeiro autor.
}

${ }^{2}$ Professor(a) Adjunto do Departamento de Agronomia da Universidade Estadual de Maringá, Paraná. Av. Colombo 5790, Bloco J-45, CEP:87020900. Maringá, PR, Brasil. E-mail: lpalbrecht@yahoo.com.br*; albraccini@ uem.br; cascapim@uem.br; marizangela_rizzatti@hotmail.com.

${ }^{3}$ Graduando do curso de Agronomia da Universidade Estadual de Maringá. E-mail: ajpalbrecht@yahoo.com.br

${ }^{4}$ Doutorando do curso de Pós-Graduação em Agronomia da Universidade Estadual de Maringá. E-mail: mcezarbarbosa@yahoo.com.br 


\section{INTRODUÇÃO}

Com o intuito de alcançar maiores retornos econômicos, de obter incrementos na produtividade da cultura, e a fim de melhorar a qualidade e composição química das sementes em níveis satisfatórios, faz-se necessária a continuidade no processo de geração de informações, provenientes da pesquisa dirigida, que avalie práticas inovadoras de manejo, como o uso de biorreguladores. Reguladores vegetais ou biorreguladores são substâncias ou associações, podendo elas ser análogos químicos de hormônios vegetais. Os reguladores vegetais possuem ampla aplicabilidade fitotécnica em inúmeras culturas, como: o milho, (Dourado Neto et al., 2004; Ferreira et al., 2007), feijão (Alleoni et al., 2000), algodão (Santos e Vieira, 2005, Albrecht et al., 2009) e essências florestais (Prado Neto et al., 2007), assim como a própria sojicultura (Klahold et al., 2006; Ávila et al., 2008; Moterle et al., 2008; Campos et al., 2009).

Várias pesquisas demonstram o efeito de biorreguladores com ação promotora na cultura da soja, como os de Vieira e Castro (2001), Klahold et al. (2006), Campos et al. (2008) e Moterle et al. (2008), que apontam resultados concernentes aos componentes da produção e desempenho das plântulas, em que as sementes foram tratadas. Porém, apenas o trabalho de Ávila et al. (2008) apresenta alguns resultados científicos que abarcam

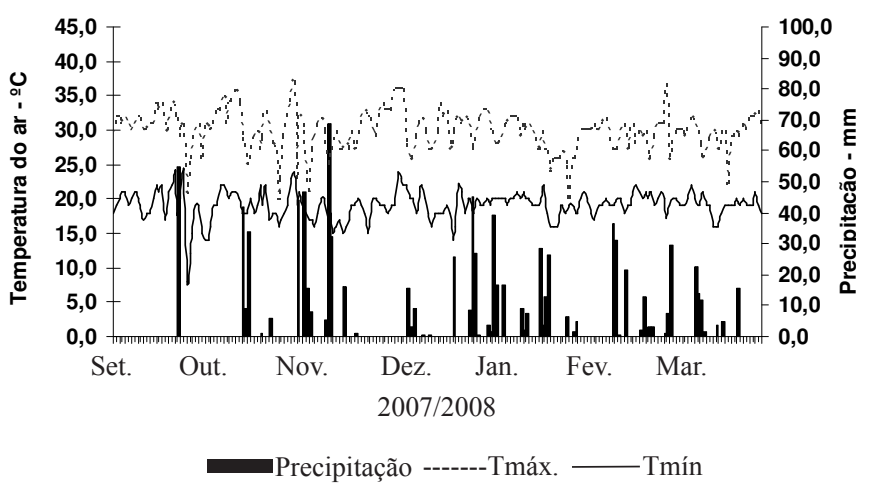

aspectos sobre a qualidade das sementes produzidas sob manejo do biorregulador.

Portanto, o presente trabalho teve por objetivo avaliar o efeito da aplicação do biorregulador Stimulate $^{\circledR}$ na qualidade fisiológica e sanitária das sementes de soja, cultivar BRS 246 RR.

\section{MATERIAL E MÉTODOS}

O experimento foi instalado no campo experimental da FEI-UEM (Fazenda Experimental de Iguatemi Universidade Estadual de Maringá), localizando-se a uma latitude de $23^{\circ} 25^{\prime}$ Sul e longitude de $51^{\circ} 57^{\prime}$ a Oeste de Greenwhich com altitude média de 540 m onde se avaliou a produtividade As avaliações de composição química dos grãos foi conduzida no Laboratório de Tecnologia de Sementes do Núcleo de Pesquisa Aplicada à Agricultura (Nupagri), pertencente ao Centro de Ciências Agrárias da Universidade Estadual de Maringá (UEM).

O solo da área experimental foi classificado como Argissolo Vermelho distróférrico de textura média (Embrapa, 2006). Segundo a classificação de Köppen, o tipo climático predominante na área é o Cfa - subtropical úmido mesotérmico. Os dados de precipitação pluvial, temperaturas máxima e mínima e umidade relativa do ar, referentes ao período de duração do experimento foram coletados diariamente na FEI-UEM (Figura 1).

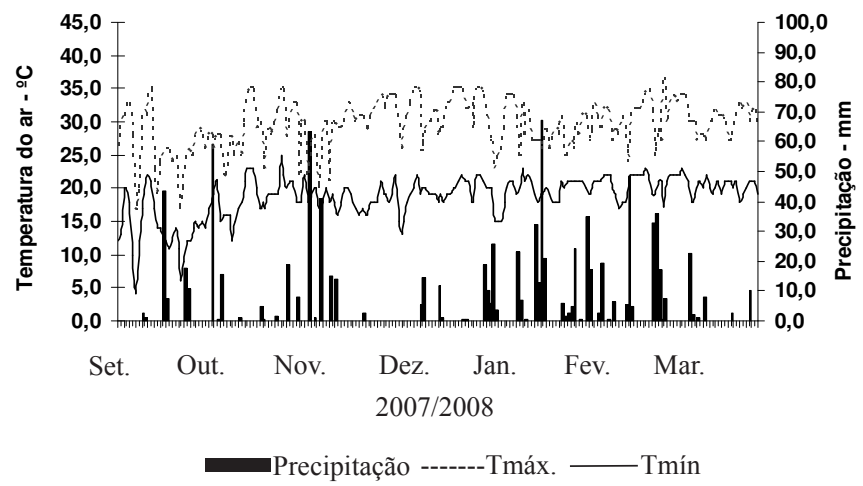

FIGURA 1. Dados climáticos diários de temperaturas máxima e mínima, precipitação pluvial, no ano agrícola 2007/2008 e 2008/2009, na Fazenda Experimental de Iguatemi (FEI).

A adubação de semeadura $(\mathrm{N}-\mathrm{P}-\mathrm{K}+\mathrm{S}+\mathrm{Ca}+$ micronutrientes) foi realizada com base na análise de solo e seguindo recomendações da Embrapa Soja (2005), objetivando produzir $3.500 \mathrm{~kg} \mathrm{ha}^{-1}$ de sementes.

Foi utilizada, no experimento, a cultivar de soja BRS
246 RR, pertencente ao grupo de maturação médio, com ciclo de aproximadamente 130 dias. A semeadura foi realizada em 20/10/2007 ( $1^{\circ}$ Ano) e 20/10/2008 (2 Ano), com espaçamento de $0,45 \mathrm{~m}$ entre as linhas, e população de 355.555 plantas ha $^{-1}$, em área de semeadura direta, 
com a cultura da aveia no inverno. As parcelas foram constituídas de seis linhas de $5 \mathrm{~m}$ de comprimento. Para as avaliações, utilizou-se área útil de $5,4 \mathrm{~m}^{2}$.

Durante o desenvolvimento da cultura, foram realizados todos os manejos fitotécnicos e fitossanitários necessários e segundo recomendações da Embrapa Soja (2005).

O arranjo dos tratamentos, para os anos agrícolas 2007/2008 e 2008/2009, foram compostos pelo tratamento de sementes, com e sem o produto Stimulate ${ }^{\circledR}$, além de cinco doses do Stimulate ${ }^{\circledR}$ aplicadas, via foliar, em dois estádios de desenvolvimento da cultura, ou seja, $V_{5}$ ou $\mathrm{R}_{3}$, constituindo-se um fatorial $2 \times 5 \times 2$. As dosagens utilizadas foram as seguintes: via tratamento de sementes - 0 e $0,500 \mathrm{~L} 100 \mathrm{~kg}^{-1}$ de sementes; pulverização foliar $0 ; 0,125 ; 0,250 ; 0,375$ e $0,500 \mathrm{~L} \mathrm{ha}^{-1}$.

O Stimulate ${ }^{\circledR}$ é um biorregulador líquido da Stoller do Brasil Ltda., composto por três reguladores vegetais na seguinte concentração: $0,005 \%$ do ácido indolbutírico IBA (análogo de auxina), 0,009\% de cinetina (citocinina) e $0,005 \%$ de ácido giberélico - $\mathrm{GA}_{3}$ (giberelina).

O tratamento de sementes com o biorregulador foi realizado por ocasião da semeadura, juntamente com a aplicação de $250 \mathrm{~mL}$ de fungicida (Vitavax-Thiran ${ }^{\circledR}$ 200 SC - Carboxin + Thiram) e $150 \mathrm{~mL}$ de CoMo (Plantinum $^{\circledR}-15 \%$ Mo e $1,5 \%$ Co), para $100 \mathrm{~kg}$ de sementes, em que, utilizando-se sacos plásticos para o condicionamento das sementes e, por meio de agitação manual, se promoveu maior contato entre as sementes e o produto. Logo após o tratamento com fungicida $+\mathrm{CoMo}$ + Stimulate ${ }^{\circledR}$, foi realizada a inoculação das sementes com o produto comercial turfoso MasterFix ${ }^{\circledR}$ (Bradyrhizobium

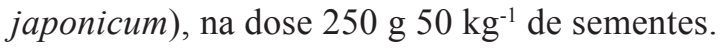

Para as aplicações foliares, efetuadas nos estádios $\mathrm{V}_{5}$ e $\mathrm{R}_{3}$, foi utilizado pulverizador costal propelido a $\mathrm{CO}_{2}$, com pressão constante de 2 BAR (ou 29 PSI), uma vazão de $0,65 \mathrm{~L} \mathrm{min.} .^{-1}$, equipado com lança contendo 1 bico leque da série Teejet tipo XR 110 02, que, trabalhando a uma altura de $50 \mathrm{~cm}$ do alvo e a uma velocidade de 1 $\mathrm{m}$ segundo ${ }^{-1}$, atingindo uma faixa aplicada de $50 \mathrm{~cm}$ de largura, propiciou um volume de calda de $200 \mathrm{~L} \mathrm{ha}^{-1}$. Foi adicionado o adjuvante Natur'l Óleo ${ }^{\circledR}$ (ésteres de ácido graxos com glicerol), na concentração de $0,5 \%$ da calda juntamente com o biorregulador.

As plantas foram colhidas manualmente, cinco a oito dias após o estádio de desenvolvimento $\mathrm{R}_{8}$. Após a colheita das plantas, as vagens foram debulhadas em máquina trilhadora estacionária, limpas com o auxílio de peneiras, secas em condições naturais e acondicionadas em sacos de papel kraft.

A qualidade fisiológica das sementes colhidas foi avaliada por meio dos testes de germinação, primeira contagem do teste de germinação (Brasil, 1992) e condutividade elétrica (Vieira e Krzyzanowski, 1999). A qualidade sanitária das sementes colhidas foi avaliada por meio do método do papel-filtro ou "blotter test" (Henning, 1994).

O delineamento experimental adotado foi em blocos completos com tratamentos casualizados, com 20 tratamentos e quatro repetições. Os tratamentos foram arranjados no esquema fatorial $2 \times 5 \times 2$ (tratamento de sementes, aplicação foliar e estádio de desenvolvimento). Os dados foram submetidos à análise de variância e todos os desdobramentos das interações foram realizados independentemente da significância ou não do teste F inicial. O mesmo teste, com 1 grau de liberdade, foi conclusivo na comparação das médias dos efeitos de tratamento de sementes e de estádios fenológicos. A análise de regressão foi utilizada para verificar o ajuste de modelos polinomiais para variáveis dependentes, em função das doses de biorregulador aplicados, via foliar, em nível de $5 \%$ de probabilidade.

\section{RESULTADOS E DISCUSSÃO}

\section{Safra 2007/2008}

As duas contagens do teste de germinação (Tabela 1) apresentaram diferenças significativas entre estádios de aplicação foliar. Contudo, ocorreu diferença entre ausência e presença de tratamento de sementes apenas para a variável primeira contagem do teste de germinação (indicativo do vigor). Destaca-se que, quando não houve tratamento de sementes, para a primeira e segunda dose do produto, aplicações foliares realizadas no estádio $R_{3}$ foram superiores às realizadas no estádio $\mathrm{V}_{5}$, tanto para germinação quanto no vigor das sementes. Além disso, pulverizações realizadas no estádio $R_{3}$, na primeira e última dose, quando não se tratou as sementes com biorregulador, o vigor das sementes, avaliado por meio da primeira contagem, foi superior.

$\mathrm{Na}$ avaliação da condutividade elétrica das sementes (Tabela 2), sucedeu diferença significativa $(P<0,05)$ no tratamento de sementes e entre os estádios de aplicação foliar, somente dentro das doses mais elevadas do Stimulate ${ }^{\circledR}$. Já, no teste de sanidade das sementes, ocorreram maiores distinções dentro das doses. 
TABELA 1. Plântulas normais obtidas na primeira contagem (vigor) e na contagem final do teste de germinação das sementes produzidas na ausência e presença de tratamento de sementes e em diferentes estádios de aplicação foliar e doses do biorregulador, no ano agrícola 2007/2008.

\begin{tabular}{|c|c|c|c|c|}
\hline \multirow[t]{2}{*}{ Doses $\left(\mathrm{mL} \mathrm{ha}^{-1}\right)$} & \multicolumn{2}{|c|}{ Sem tratamento de sementes } & \multicolumn{2}{|c|}{ Com tratamento de sementes } \\
\hline & Foliar $-\mathrm{V}_{5}$ & Foliar $-\mathrm{R}_{3}$ & Foliar - $\mathrm{V}_{5}$ & Foliar - $\mathrm{R}_{3}$ \\
\hline \multicolumn{5}{|c|}{ Germinação - contagem final (\% plântulas normais) } \\
\hline 0 & $69,00 \mathrm{Ab}$ & $84,50 \mathrm{Aa}$ & $76,00 \mathrm{Aa}$ & $76,50 \mathrm{Aa}$ \\
\hline 125 & $68,75 \mathrm{Ab}$ & $81,50 \mathrm{Aa}$ & $74,50 \mathrm{Aa}$ & $75,25 \mathrm{Aa}$ \\
\hline 250 & $69,00 \mathrm{Aa}$ & $76,75 \mathrm{Aa}$ & $76,75 \mathrm{Aa}$ & $77,25 \mathrm{Aa}$ \\
\hline 375 & $82,75 \mathrm{Aa}$ & $74,75 \mathrm{Aa}$ & $85,50 \mathrm{Aa}$ & $69,00 \mathrm{Ab}$ \\
\hline 500 & $82,75 \mathrm{Aa}$ & $79,75 \mathrm{Aa}$ & $75,00 \mathrm{Aa}$ & $71,75 \mathrm{Aa}$ \\
\hline Média & 74,45 & 77,55 & 79,45 & 73,95 \\
\hline $\mathrm{CV}(\%)$ & 9,03 & & & \\
\hline \multicolumn{5}{|c|}{ Vigor - primeira contagem (\% plântulas normais) } \\
\hline 0 & $63,50 \mathrm{Ab}$ & $81,00 \mathrm{Aa}$ & $72,75 \mathrm{Aa}$ & $71,25 \mathrm{Ba}$ \\
\hline 125 & $63,00 \mathrm{Ab}$ & $78,00 \mathrm{Aa}$ & $70,25 \mathrm{Aa}$ & $70,50 \mathrm{Aa}$ \\
\hline 250 & $61,75 \mathrm{Ba}$ & $71,00 \mathrm{Aa}$ & $75,00 \mathrm{Aa}$ & $71,25 \mathrm{Aa}$ \\
\hline 375 & $79,00 \mathrm{Aa}$ & $72,25 \mathrm{Aa}$ & $79,75 \mathrm{Aa}$ & $65,25 \mathrm{Ab}$ \\
\hline 500 & $75,50 \mathrm{Aa}$ & $75,50 \mathrm{Aa}$ & $71,75 \mathrm{Aa}$ & $62,50 \mathrm{Ba}$ \\
\hline Média & 68,55 & 75,55 & 73,90 & 68,15 \\
\hline $\mathrm{CV}(\%)$ & 9,59 & & & \\
\hline
\end{tabular}

*Letras maiúsculas iguais, na linha, entre sem e com tratamento de sementes e, dentro de cada estádio e dose, não diferem entre si a 5\% de probabilidade, pelo teste F. Letras minúsculas iguais, na linha, entre estádios de aplicação e, dentro de cada tratamento de sementes e dose, não diferem entre si a 5\% de probabilidade, pelo teste $\mathrm{F}$.

TABELA 2. Condutividade elétrica e sanidade das sementes produzidas na ausência e presença de tratamento de sementes e em diferentes estádios de aplicação foliar e doses do biorregulador, no ano agrícola 2007/2008.

\begin{tabular}{|c|c|c|c|c|}
\hline \multirow[t]{2}{*}{ Doses $\left(\mathrm{mL} \mathrm{ha}^{-1}\right)$} & \multicolumn{2}{|c|}{ Sem tratamento de sementes } & \multicolumn{2}{|c|}{ Com tratamento de sementes } \\
\hline & Foliar $-\mathrm{V}_{5}$ & Foliar $-\mathrm{R}_{3}$ & Foliar $-\mathrm{V}_{5}$ & Foliar - $\mathrm{R}_{3}$ \\
\hline \multicolumn{5}{|c|}{ Condutividade elétrica $\left(\mu \mathrm{S} \mathrm{cm}^{-1} \mathrm{~g}^{-1}\right)$} \\
\hline 0 & $145,25 \mathrm{Aa}$ & $136,75 \mathrm{Aa}$ & $122,25 \mathrm{Aa}$ & $140,00 \mathrm{Aa}$ \\
\hline 125 & $129,25 \mathrm{Aa}$ & $149,00 \mathrm{Aa}$ & $122,75 \mathrm{Aa}$ & $160,75 \mathrm{Aa}$ \\
\hline 250 & $118,25 \mathrm{Aa}$ & $143,25 \mathrm{Aa}$ & $121,25 \mathrm{Aa}$ & $146,25 \mathrm{Aa}$ \\
\hline 375 & $151,00 \mathrm{Aa}$ & $135,50 \mathrm{Aa}$ & $113,50 \mathrm{Ab}$ & $166,50 \mathrm{Aa}$ \\
\hline 500 & $161,50 \mathrm{Aa}$ & $137,00 \mathrm{Aa}$ & $128,75 \mathrm{Ab}$ & $232,75 \mathrm{Ba}$ \\
\hline $\mathrm{CV}(\%)$ & 21,11 & & & \\
\hline \multicolumn{5}{|c|}{ Sanidade (\% total de fungos) } \\
\hline 0 & $64,00 \mathrm{Aa}$ & $47,50 \mathrm{Aa}$ & $33,75 \mathrm{Bb}$ & $53,00 \mathrm{Aa}$ \\
\hline 125 & $80,00 \mathrm{Aa}$ & $28,00 \mathrm{Bb}$ & $45,75 \mathrm{Bb}$ & $82,25 \mathrm{Aa}$ \\
\hline 250 & $56,00 \mathrm{Aa}$ & $37,75 \mathrm{Aa}$ & $46,75 \mathrm{Aa}$ & $45,00 \mathrm{Aa}$ \\
\hline 375 & $74,00 \mathrm{Aa}$ & $35,75 \mathrm{Bb}$ & $25,00 \mathrm{Bb}$ & $62,25 \mathrm{Aa}$ \\
\hline 500 & $99,00 \mathrm{Aa}$ & $69,75 \mathrm{Ab}$ & $40,50 \mathrm{Bb}$ & $83,75 \mathrm{Aa}$ \\
\hline $\mathrm{CV}(\%)$ & 23,84 & & & \\
\hline
\end{tabular}

*Letras maiúsculas iguais, na linha, entre sem e com tratamento de sementes e, dentro de cada estádio e dose, não diferem entre si a 5\% de probabilidade, pelo teste F. Letras minúsculas iguais, na linha, entre estádios de aplicação e, dentro de cada tratamento de sementes e dose, não diferem entre si a 5\% de probabilidade, pelo teste $\mathrm{F}$. 
Para a variável condutividade elétrica, salientase que os valores observados dentro de tratamento de sementes com biorregulador e para as duas últimas doses, que as aplicações realizadas em $\mathrm{R}_{3}$, em comparação com a pulverização foliar no $\mathrm{V}_{5}$, propiciaram maiores valores de condutividade elétrica das sementes, o que indica maior lixiviação de íons; portanto, infere-se que tais sementes estejam com menor potencial fisiológico.

Ressalta-se, dentre as diferenças apontadas pelo teste $\mathrm{F}(P<0,05)$ na variável sanidade das sementes, que quando aplicações foram realizadas no $\mathrm{V}_{5}$, com a exceção da dose de $250 \mathrm{~mL} \mathrm{ha}^{-1}$, aconteceu diferença entre ausência e presença de tratamento de sementes com biorregulador, e a ausência de tratamento permitiu a obtenção de sementes com qualidade sanitária inferior do que a presença de tratamento. Quanto às distinções entre estádios, mencionam-se as ocorridas dentro das duas últimas doses do produto, tanto para ausência como presença de tratamento de sementes. Destaca-se que aplicações realizadas no estádio $\mathrm{R}_{3}$ permitiram a obtenção de sementes com menor porcentagem de infecção por fungos, quando não foi efetuado o tratamento de sementes com biorregulador. Ao contrário, aplicações realizadas no estádio $\mathrm{V}_{5}$ propiciaram a produção de sementes com qualidade sanitária superior, na presença de tratamento de sementes (Tabela 2).

O ajuste de modelos para análise de regressão (Figuras 2, 3, 4 e 5) somente foi possível dentro dos tratamentos em que o biorregulador foi usado nas sementes, para a variável condutividade elétrica, e nos tratamentos em que não foi usado nas sementes, para as duas contagens do teste de germinação e no teste de sanidade.

Os resultados referentes à regressão polinomial para o tratamento quantitativo dose (dentro de tratamento de sementes e estádio de aplicação), possibilitou vislumbrar que a aplicação de biorregulador na fase vegetativa, mais especificamente em $\mathrm{V}_{5}$, possui efeito na germinação e vigor das sementes (Figuras 2 e 3), pois a resposta foi linear crescente. Porém, a resposta sucedeu quando não ocorreu o tratamento de sementes com o biorregulador Stimulate ${ }^{\circledR}$. Esses resultados não corroboram plenamente com Ávila et al. (2008), que obtiveram alguns valores negativos, em relação à testemunha, quanto à germinação das sementes de soja e no teste de classificação do vigor das plântulas, utilizando o mesmo biorregulador, só que na formulação concentrada.

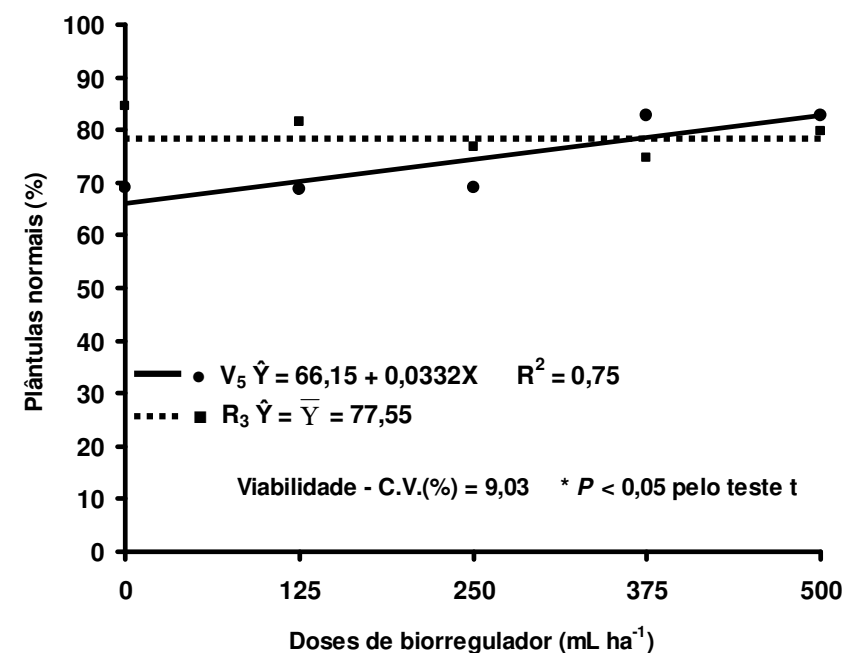

FIGURA 2. Regressão polinomial da porcentagem das plântulas normais obtida no teste de germinação das sementes (contagem final), em função de diferentes doses do biorregulador aplicadas, via foliar, em diferentes estádios de desenvolvimento e sem tratamento de sementes, no ano agrícola 2007/2008.

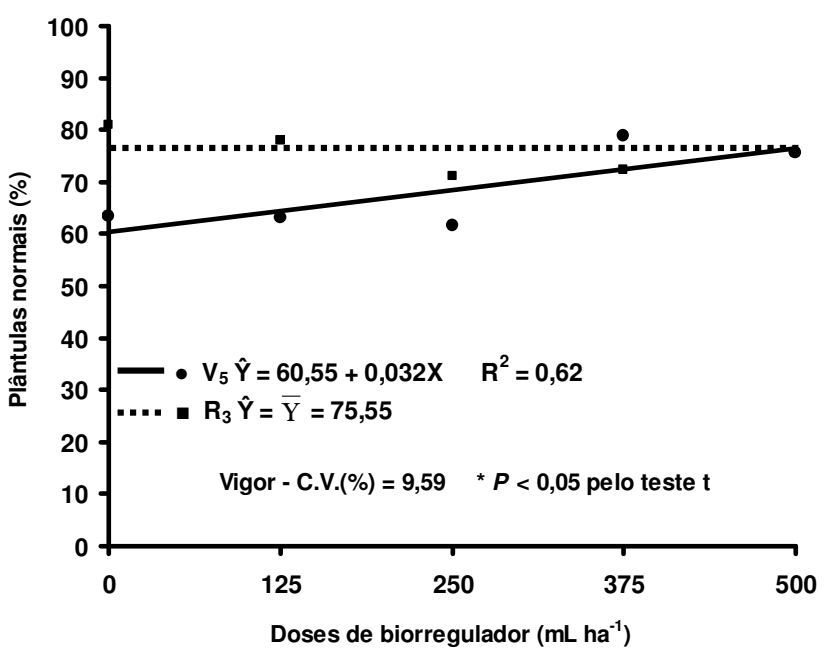

FIGURA 3. Regressão polinomial da percentagem das plântulas normais obtida na primeira contagem (vigor) do teste de germinação das sementes, em função de diferentes doses do biorregulador aplicadas, via foliar, em diferentes estádios de desenvolvimento e sem tratamento de sementes, no ano agrícola 2007/2008. 


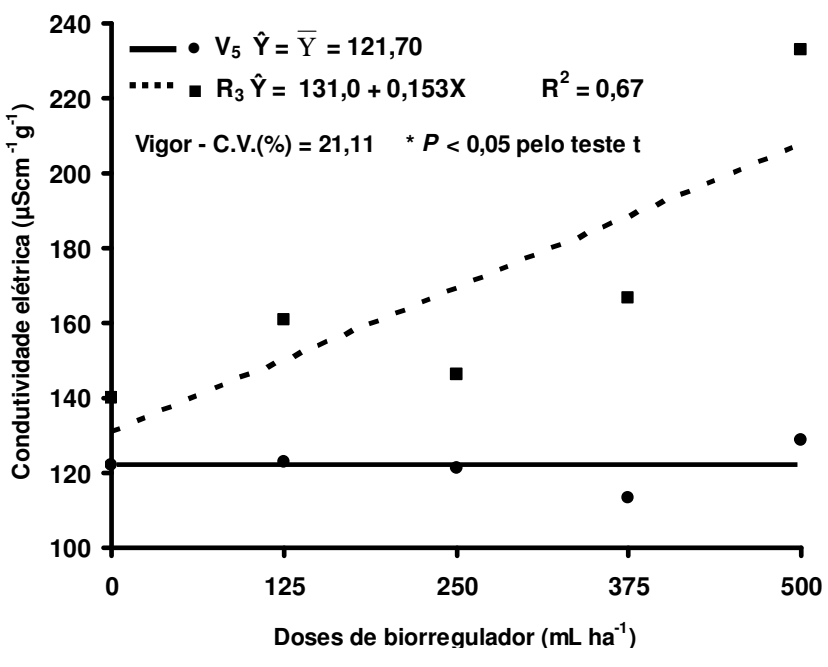

FIGURA 4. Regressão polinomial da condutividade elétrica das sementes, em função de diferentes doses do biorregulador aplicadas, via foliar, em diferentes estádios de desenvolvimento e com tratamento de sementes, no ano agrícola 2007/2008.

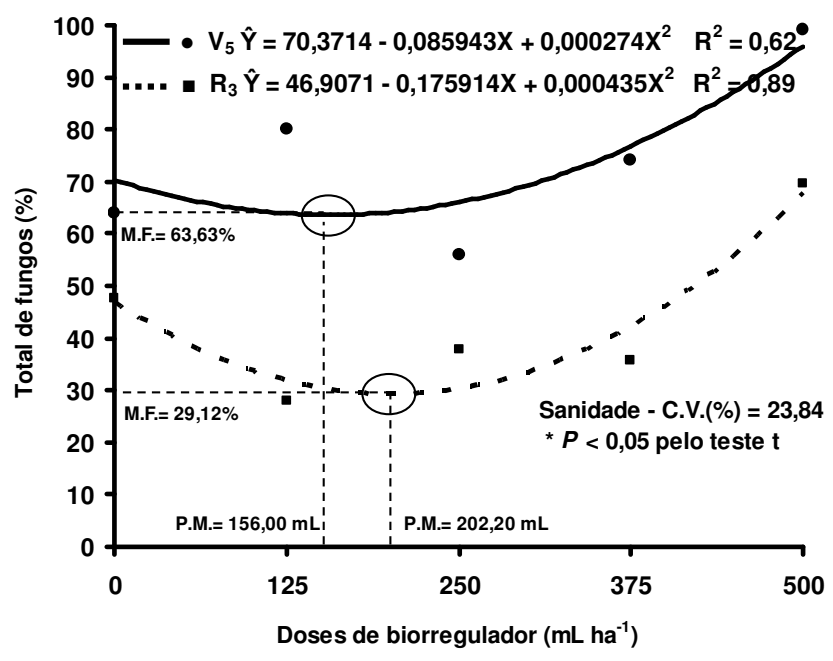

FIGURA 5. Regressão polinomial da porcentagem total de fungos obtidos no teste de sanidade das sementes, em função de diferentes doses do biorregulador aplicadas, via foliar, em diferentes estádios de desenvolvimento e sem tratamento de sementes, no ano agrícola 2007/2008.
Os valores de condutividade elétrica (Figura 4) indicam que, aumentos nas doses do biorregulador aplicadas via foliar no estádio $\mathrm{R}_{3}$, quando somadas ao tratamento de sementes, podem prejudicar o vigor das sementes, uma vez que a condutividade elétrica aumentou em $0,153 \mu \mathrm{S} \mathrm{cm}^{-1} \mathrm{~g}^{-1}$ (coeficiente angular) a cada $1 \mathrm{~mL}$ $\mathrm{ha}^{-1}$ aplicado na fase reprodutiva. O potencial fisiológico diminuiu linearmente com o incremento da dose via foliar no estádio reprodutivo, quando foi realizado o tratamento das sementes com biorregulador. Essa condição denota menor qualidade fisiológica das sementes, quando biorregulador empregado em $\mathrm{R}_{3}$.

Valores superiores de condutividade elétrica indicam problemas na permeabilidade seletiva das membranas (Marcos Filho, 2005), identificado pela maior presença de íons que conduzem a corrente elétrica na solução em que foram embebidas as sementes. Danos às membranas podem derivar do processo deteriorativo nas sementes, e esse está atrelado à presença de radicais livres procedentes do metabolismo. Um desbalanço nos níveis hormonais, ocasionado pela introdução de análogos, via exógena, pode levar a distúrbios metabólicos, os quais potencialmente geram radicais livres.

Supõe-se que os mesmos reguladores vegetais que podem incrementar a síntese de substâncias antioxidantes, também induzir, quando mal manejados, a produção de radicais livres. Porém, as menções apenas se limitam a esfera das especulações científicas, as quais ainda precisam ser melhores esclarecidas experimentalmente.

Por outro lado, a análise da sanidade das sementes (Figura 5) permitiu determinar uma dose ótima (156,0 $\mathrm{mL} \mathrm{ha}^{-1} \mathrm{em} \mathrm{V}_{5}$ e $202,2 \mathrm{~mL} \mathrm{ha}^{-1} \mathrm{em} \mathrm{R}_{3}$, na ausência de tratamento de sementes), no qual é possível obter sementes com a menor porcentagem de patógenos, portanto, melhor qualidade sanitária. Esses resultados confirmam o exposto por Ávila et al. (2008) que indicaram alteração nos valores de incidência de fungos nas sementes de soja com o uso do mesmo biorregulador, na formulação concentrada.

Os resultados obtidos demonstram a influência do biorregulador na cultura da soja, pelos efeitos notados na qualidade das sementes, o que corrobora parcialmente com a literatura pertinente, no que concerne aos aspectos agronômicos e qualidade das sementes sob tratamento com biorregulador (Vieira e Castro, 2001; Castro, 2006; Klahold et al., 2006; Ávila et al., 2008; Campos et al., 2008; Campos et al., 2009), bem como no que se refere aos poucos trabalhos disponíveis na literatura, oriundos da avaliação da qualidade das sementes produzidas sob 
manejo com biorregulador (Ávila et al., 2008).

A questão a ressaltar é que nem sempre o tratamento de sementes contribui na elevação na qualidade das sementes, quando associado a aplicações foliares, sobretudo no estádio $\mathrm{R}_{3}$, conforme indicado na Figura 4, relacionado à condutividade elétrica das sementes. Outro aspecto a ser observado se refere à germinação das sementes, que pode ser aumentada com o uso do biorregulador, porém, quando a aplicação é realizada via foliar no estádio $\mathrm{V}_{5}$, somente quando não ocorre tratamento de sementes. No entanto, doses aplicadas no estádio vegetativo, assim como no reprodutivo, não devem ser muito elevadas, causando prejuízo na qualidade sanitária das sementes de soja, quando na ausência de tratamento de sementes com biorregulador.

\section{Safra 2008/2009}

$\mathrm{Na}$ Tabela 3 encontram-se as médias obtidas nos efeitos principais pertinentes a cada fator avaliado. Reiterase a ausência de distinção entre os valores pelo teste $\mathrm{F}$, a 5\% de probabilidade. Observa-se que apenas para a variável sanidade das sementes houve diferença estatística dentro do efeito principal dose (Figura 6). Quanto à variável vigor das sementes, obtido na primeira contagem do teste de germinação, os resultados oriundos do desdobramento encontram-se na Tabela 4 e na Figura 7.

TABELA 3. Qualidade das sementes de soja sob o efeito do uso de biorregulador em tratamento de sementes e aplicação foliar em dois estádios de desenvolvimento, no ano agrícola 2008/2009.

\begin{tabular}{ccccc}
\hline \multirow{2}{*}{ Tratamentos } & Germinação & Vigor - primeira contagem & Condutividade Elétrica & Sanidade \\
\cline { 2 - 5 } & (\% plântulas normais) & (\% plântulas normais) & $\left(\mu \mathrm{S} \mathrm{cm}^{-1} \mathrm{~g}^{-1}\right)$ & $(\%$ total de fungos $)$ \\
\hline TS & & & & \\
\hline Sem & $75,98 \mathrm{~A}$ & $59,95 \mathrm{~A}$ & $136,43 \mathrm{~A}$ & $55,63 \mathrm{~A}$ \\
Com & $78,50 \mathrm{~A}$ & $60,05 \mathrm{~A}$ & $135,73 \mathrm{~A}$ & $54,55 \mathrm{~A}$ \\
\hline Foliar & & & & \\
\hline $\mathrm{V}_{5}$ & $75,53 \mathrm{~A}$ & $59,70 \mathrm{~A}$ & $134,50 \mathrm{~A}$ & $55,30 \mathrm{~A}$ \\
$\mathrm{R}_{3}$ & $75,30 \mathrm{~A}$ & $60,30 \mathrm{~A}$ & $137,65 \mathrm{~A}$ & $54,88 \mathrm{~A}$ \\
\hline Média Geral & 75,41 & 60,00 & 136,08 & 55,09 \\
\hline CV $(\%)$ & 7,63 & 8,22 & 13,58 & 19,02 \\
\hline
\end{tabular}

*Letras maiúsculas iguais, na coluna, para cada variável resposta e dentro de cada tratamento, não diferem entre si a $5 \%$ de probabilidade, pelo teste $\mathrm{F}$.

TABELA 4. Plântulas normais obtidas na primeira contagem do teste de germinação das sementes produzidas na ausência e presença de tratamento de sementes e em diferentes estádios de aplicação foliar e doses do biorregulador, no ano agrícola 2008/2009.

\begin{tabular}{ccccc}
\hline \multirow{2}{*}{$\begin{array}{c}\text { Doses } \\
\left(\mathrm{mL} \mathrm{ha}^{-1}\right)\end{array}$} & \multicolumn{2}{c}{ Sem tratamento de sementes } & \multicolumn{2}{c}{ Com tratamento de sementes } \\
\cline { 2 - 4 } & Foliar $-\mathrm{V}_{5}$ & \multicolumn{2}{c}{ Foliar $-\mathrm{R}_{3}$} & \multicolumn{2}{c}{ Foliar $-\mathrm{V}_{5}$} & Foliar $-\mathrm{R}_{3}$ \\
\cline { 2 - 4 } & & \multicolumn{2}{c}{ Vigor - primeira contagem $(\%$ plântulas normais $)$} \\
\hline 0 & $59,50 \mathrm{Aa}$ & $60,50 \mathrm{Aa}$ & $54,50 \mathrm{Aa}$ & $61,00 \mathrm{Aa}$ \\
25 & $64,50 \mathrm{Aa}$ & $63,00 \mathrm{Aa}$ & $58,50 \mathrm{Aa}$ & $62,00 \mathrm{Aa}$ \\
375 & $67,50 \mathrm{Aa}$ & $58,00 \mathrm{Ab}$ & $61,00 \mathrm{Aa}$ & $60,50 \mathrm{Aa}$ \\
500 & $54,50 \mathrm{Aa}$ & $54,50 \mathrm{Ba}$ & $60,50 \mathrm{Aa}$ & $62,50 \mathrm{Ab}$ \\
\hline Média & $55,50 \mathrm{Aa}$ & $62,00 \mathrm{Aa}$ & $61,00 \mathrm{Aa}$ & $61,00 \mathrm{Aa}$ \\
\hline CV $(\%)$ & 60,30 & 59,60 & 59,10 & 61,00 \\
\hline
\end{tabular}

*Letras maiúsculas iguais, na linha, entre sem e com tratamento de sementes e, dentro de cada estádio e dose, não diferem entre si a 5\% de probabilidade, pelo teste F. Letras minúsculas iguais, na linha, entre estádios de aplicação e, dentro de cada tratamento de sementes e dose, não diferem entre si a 5\% de probabilidade, pelo teste $\mathrm{F}$. 


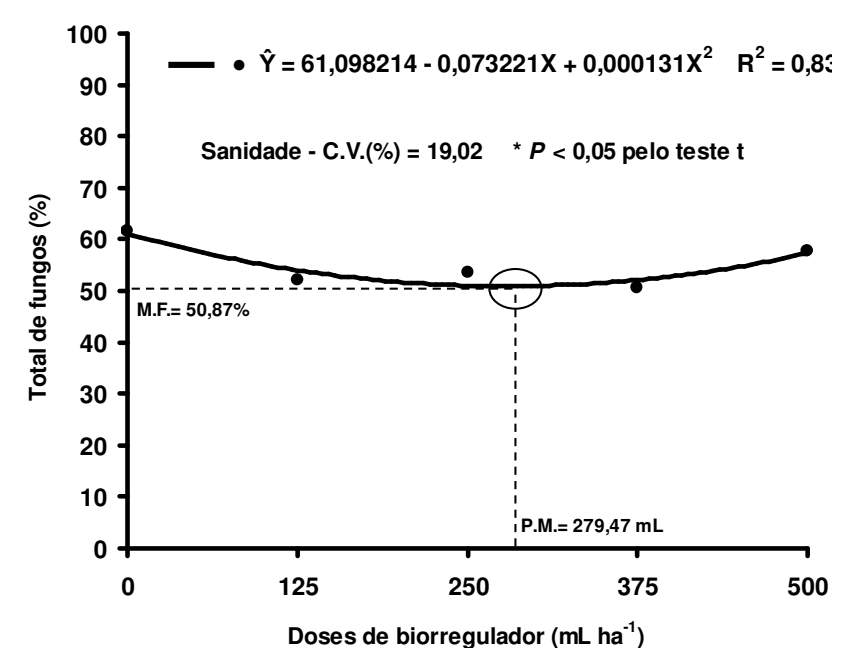

FIGURA 6. Regressão polinomial da sanidade das sementes, em função de diferentes doses do biorregulador aplicadas, via foliar, em diferentes estádios de desenvolvimento e na ausência e presença de tratamento de sementes, no ano agrícola 2008/2009.

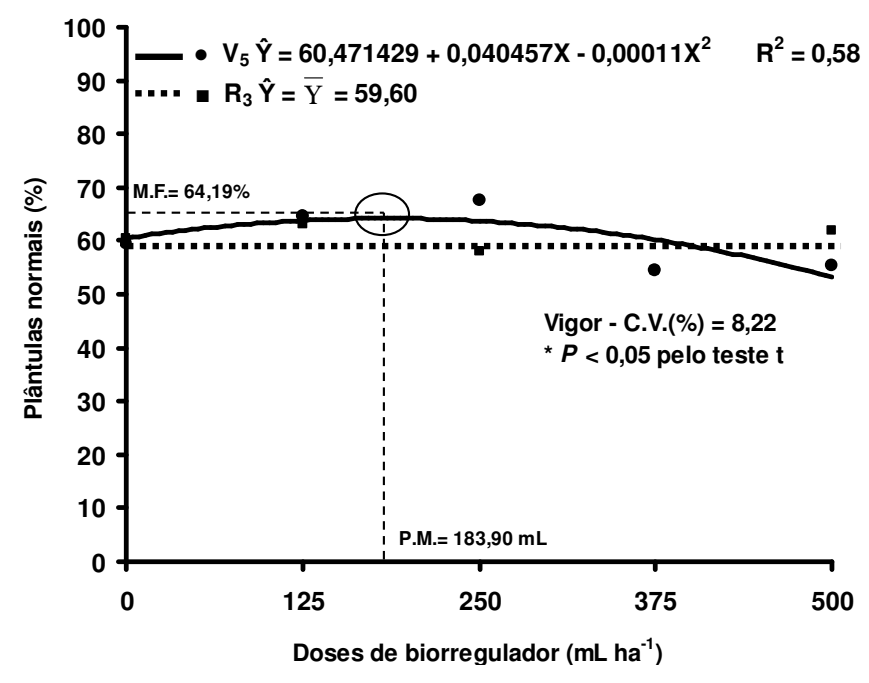

FIGURA 7. Regressão polinomial da porcentagem das plântulas normais obtidas na primeira contagem (vigor) do teste de germinação das sementes, em função de diferentes doses do biorregulador aplicadas, via foliar, em diferentes estádios de desenvolvimento e ausência de tratamento de sementes, no ano agrícola 2008/2009.
Os resultados do vigor das sementes de soja, apresentados na Tabela 4, caracterizaram diferença significativa entre ausência e presença de tratamento de sementes. Nota-se que o tratamento das sementes com $500 \mathrm{~mL} 100 \mathrm{~kg}^{-1}$ de sementes mostrou-se eficiente, quando associado com aplicação foliar em $\mathrm{R}_{3}$ e na dose de $375 \mathrm{~mL} \mathrm{ha}^{-1}$ do produto Stimulate ${ }^{\circledR}$. No tocante às distinções entre estádios fenológicos, observase que pulverizações realizadas no estádio $\mathrm{V}_{5}$ foram superiores às realizadas no $\mathrm{R}_{3}$, quando foram usadas as doses de 250 e $375 \mathrm{~mL} \mathrm{ha}^{-1}$, na ausência e presença de tratamento de sementes, respectivamente. Portanto, o tratamento das sementes e as aplicações foliares em $\mathrm{V}_{5}$ tendem a apresentar resultados superiores diante das condições experimentais ocorridas no ano agrícola de 2008/2009.

No que concerne ao desdobramento dos tratamentos quantitativos da mesma variável mencionada anteriormente (Figura 7), observa-se pela análise de regressão que apenas aplicações foliares em $V_{5}$ apresentaram efeito significativo em resposta às doses utilizadas e, particularmente quando não ocorreu o tratamento de sementes com o biorregulador. O modelo matemático ajustado permitiu obter um ponto de máximo igual a $183,90 \mathrm{~mL} \mathrm{ha}^{-1}$, com o máximo da função em $64,19 \%$ de plântulas normais.

Já na Figura 6, observa-se o comportamento quadrático obtido para a variável sanidade das sementes, em função das doses aplicadas, independente do estádio de aplicação ou do tratamento de sementes que poderia ter precedido o uso foliar do produto. A derivada da equação permitiu obter um ponto de mínimo (PM) de $279,47 \mathrm{~mL} \mathrm{ha}^{-1}$, no qual o mínimo da função (MF) foi de $50,87 \%$ de fungos totais, ou seja, o ponto em que foi obtida a melhor sanidade das sementes em respostas às diferentes doses.

Menciona-se o fato de que algumas das respostas favoráveis ao uso do biorregulador tenham ocorrido quando as aplicações foliares foram realizadas no estádio $\mathrm{V}_{5}$, em ambos as safras. Focando a qualidade fisiológica, é pertinente ressaltar que enquanto as respostas significativas na safra 2007/2008 foram lineares, as apresentadas na última safra caracterizaram comportamento quadrático.

Discorrendo sobre a sanidade das sementes, é válido caracterizar que para ambos os anos agrícolas, o biorregulador avaliado apresentou potencial de elevar a sanidade das sementes, por meio do ajuste de equações 
quadráticas pela análise de regressão polinomial. Porém, na safra 2007/2008, a sanidade foi melhorada tanto no estádio $\mathrm{V}_{5}$ como em $\mathrm{R}_{3}$; no entanto, quando não houve tratamento de sementes. Em contrapartida, no ano agrícola de 2008/2009, a sanidade das sementes de soja foi influenciada pelas doses, não ocorrendo diferenças para doses dentro de estádio de aplicação foliar do produto e do tratamento de sementes.

Os resultados obtidos por outros autores (Ávila et al., 2008; Campos et al., 2008; Campos et al., 2009) com o mesmo produto, ou com outros reguladores aplicados exogenamente, vem atestar que há real possibilidade do biorregulador Stimulate ${ }^{\circledR}$ alterar, não só o desempenho agronômico da soja, mas também produzir sementes com diferenciado potencial fisiológico e incidência de patógenos.

Plantas que possuem um balanço hormonal equilibrado possivelmente estarão crescendo adequadamente, tanto a parte aérea com o sistema radicular, com bom desenvolvimento de suas estruturas vegetativas e reprodutivas, com seu aparato fotossintético apto a gerar fotoassimilados para incremento na fotossíntese líquida e, assim, permitir maior acúmulo de biomassa e apresentar maior tolerância a estresses ambientais; estas plantas provavelmente irão gerar sementes com maior probabilidade de apresentar melhor qualidade fisiológica e sanitária.

Um adequado balanço hormonal, no qual os biorreguladores podem contribuir, potencialmente cria condições para a produção adequada de compostos primários e secundários. Metabólitos e demais moléculas originárias do metabolismo secundário podem possuir expressivo papel na qualidade das sementes. Por exemplo, incrementos nos teores de lignina no tegumento, podem possibilitar condições de menor suscetibilidade ao dano mecânico das sementes (Alvarez, 1994), bem como minimizar a infecção por patógenos, por compor ou configurar uma barreira física (Marcos Filho, 2005). Outros compostos secundários, como os que possuem ação fitoalexínica, possivelmente aumentarão a defesa química das plantas contra microrganismos patogênicos (Taiz e Zeiger, 2009).

Baixas concentrações de lignina e de flavonoides são também responsáveis pela diminuição na resistência das plantas às doenças (Rizzardi et al., 2003; Taiz e Zeiger, 2009). O estímulo a mecanismos de defesa envolve reações da planta ligadas à ativação de genes de defesa para reação de hipersensibilidade, resistência sistêmica adquirida e produção de lignina, enzimas hidrolíticas e fitoalexinas (Dangl et al., 2000; Taiz e Zeiger, 2009).

Portanto, atualmente se conhece o efeito direto dos biorreguladores sobre a germinação e vigor das sementes, quando os mesmos são aplicados previamente sobre as mesmas e avalia-se em laboratório, casa-de-vegetação e, até mesmo, em campo o desempenho das plântulas resultantes (Vieira e Castro, 2001; Castro, 2006; Castro et al., 2008). Porém, pouco ainda se conhece sobre o efeito de aplicações, seja em tratamento de sementes ou no decorrer do desenvolvimento da cultura, na qualidade fisiológica e sanitária das sementes produzidas sob esse tipo de manejo. Infere-se apenas que, sementes bem formadas, em um determinado sistema de cultivo, podem gerar sementes com elevada desempenho fisiológica e qualidade sanidade satisfatória (Marcos Filho, 2005); nesse quesito, a utilização de biorreguladores no manejo da cultura potencialmente contribuiria na melhoria da qualidade das sementes. Deste modo, resultados como os mencionados anteriormente vêm preencher uma lacuna na pesquisa pertinente.

\section{CONCLUSÕES}

O biorregulador utilizado altera a qualidade das sementes, diminuindo o vigor com o incremento das doses na fase reprodutiva, quando associado ao tratamento de sementes, ou aumenta a porcentagem de plântulas normais e a sanidade, quando aplicado, via foliar, sem o tratamento das sementes, sobretudo quando as aplicações foliares ocorrem em $\mathrm{V}_{5}$.

\section{REFERÊNCIAS}

ALBRECHT, L.P.; BRACCINI, A.L.; ÁVILA，M.R.; BARBOSA, M.C.; RICCI, T.T.; ALBRECHT, A.J.P. Aplicação de biorregulador na produtividade do algodoeiro e qualidade de fibra. Scientia Agraria, v.10, n.3, p.191198, 2009.

ALLEONI, B.; BOSQUEIRO, M.; ROSSI, M. Efeito dos reguladores vegetais de Stimulate no desenvolvimento e produtividade do feijoeiro (Phaseolus vulgaris L.). Publicatio UEPG, v.6, n.1, p.23-35, 2000.

ALVAREZ, P.J. Relação entre o conteúdo de lignina no tegumento de sementes de soja e sua relação ao dano mecânico. 1994. 43f. Dissertação (Mestrado em Agronomia) - Universidade Estadual de Londrina, Londrina, 1994. 
ÁVILA, M.R.; BRACCINI, A.L.; SCAPIM, C.A.; ALBRECHT, L.P.; TONIN, T.A.; STÜLP, M. Bioregulator application, agronomic efficiency, and quality of soybean seeds. Scientia Agricola, v.65, n.6, p.567-691, 2008.

BRASIL. Ministério da Agricultura e Reforma Agrária. Secretaria Nacional de Defesa Agropecuária. Departamento Nacional de Defesa Vegetal. Coordenação de Laboratório Vegetal. Regras para análise de sementes. Brasília, DF, 1992. 365p.

CAMPOS, M.F.; ONO, E.O.; BOARO, C.S.F.; RODRIGUES, J.D. Análise de crescimento em plantas de soja tratadas com substâncias reguladoras. Revista Biotemas, v.21, n.3, p.53-63, 2008.

CAMPOS, M.F.; ONO, E.O.; RODRIGUES, J.D. Desenvolvimento da parte aérea de plantas de soja em função de reguladores vegetais. Revista Ceres, v.56, n.1, p. 74-79, 2009.

CASTRO, G.S.A.; BOGIANI, J.C.; SILVA, M.G.; GAZOLA, E.; ROSOLEM, C.A. Tratamento de sementes de soja com inseticidas e um bioestimulante. Pesquisa Agropecuária Brasileira, v.43, n.10, p.1311-1318, 2008.

CASTRO, P.R.C. Agroquímicos de controle hormonal na agricultura tropical. Piracicaba: Esalq, 2006. 46p.

DANGL, J.L.; DIETRICH, R.A.; THOMAS, H. Senescence and programmed cell death. In: BUCHANAN, B.B.; GRUISSEM, W.; JONES, R.L. Biochemistry and molecular biology of plants. Rockville: American Society of Plant Physiologists, 2000. p.1044-1100.

DOURADO NETO, D.; DARIO, G.J.A.; VIEIRA JUNIOR, P.A.; MANFRON, P.A.; MARTIN, T.N.; GARCIA, R. A. Aplicação e influência do fitorregulador no crescimento das plantas de milho. Revista da FZVA, v.11, n.1, p.1-9, 2004.

EMBRAPA SOJA. Tecnologias de produção de soja - Paraná - 2006. Londrina: Embrapa Soja, 2005. 208p. (Embrapa Soja. Sistemas de Produção, 8).

EMPRESA BRASILEIRA DE PESQUISA AGROPECUÁRIA - EMBRAPA.Centro Nacional de Pesquisa de Solos. Sistema Brasileiro de Classificação de Solos. 2.ed. Rio de Janeiro: Embrapa, 2006. 306p.

FERREIRA, L.A.; OLIVEIRA, J.A.; VON PINHO, É.V.R.; QUEIROZ, D.L. Bioestimulante e fertilizante associados ao tratamento de sementes de milho. Revista Brasileira de Sementes, v.29, n.2, p.80-89, 2007.
HENNING, A.A. Patologia de sementes. Londrina: EMBRAPA - CNPSo, 1994. 43p. (EMBRAPA - CNPSo. Documentos, 90).

KLAHOLD, C.A.; GUIMARÃES, V.F.; ECHER, M.M.; KLAHOLD, A.; ROBINSON L.C., BECKER, A. Resposta da soja (Glycine max (L.) Merrill) à ação de bioestimulante. Acta Scientiarum. Agronomy, v.28, n.2, p.179-185, 2006.

MARCOS FILHO, J. Fisiologia de sementes de plantas cultivadas. Piracicaba: Fealq, 2005. 495p.

MOTERLE, L.M.; SANTOS, R.F.; BRACCINI, A.L.; SCAPIM, C.A.; BARBOSA, M.C. Efeito da aplicação de biorregulador no desempenho agronômico e produtividade da soja. Acta Scientiarum. Agronomy, v.30, supl., p.701709, 2008.

PRADO NETO, M.; DANTAS, A.C.V.L.; VIEIRA, E.L.; ALMEIDA, V.O. Germinação de sementes de jenipapeiro submetidas à pré-embebição em regulador e estimulante vegetal. Ciência e Agrotecnologia, v.31, n.3, p.693-698, 2007.

RIZZARDI, M.A.; FLECK, N.G.; AGOSTINETTO, D.; BALBINOT JUNIOR, A.A. Ação de herbicidas sobre mecanismos de defesa das plantas aos patógenos. Ciência Rural, v.33, n.5, p.957-965. 2003.

SANTOS, C.M.G.; VIEIRA, E.L. Efeito de bioestimulante na germinação de sementes, vigor de plântulas e crescimento inicial do algodoeiro. Magistra, v.17, n.3, p.124-130, 2005 .

TAIZ, L.; ZEIGER, E. Fisiologia vegetal. 4.ed. Porto Alegre: Artmed, 2009.

VIEIRA, E.L.; CASTRO, P.R.C. Ação de bioestimulante na germinação de sementes, vigor de plântulas, crescimento radicular e produtividade de soja. Revista Brasileira de Sementes, v.23, n.2, p.222-228, 2001.

VIEIRA, R.D.; KRZYZANOWSKI, F.C. Teste de condutividade elétrica. In: KRZYZANOWSKI, F.C.; VIEIRA, R.D.; FRANÇA NETO, J.B. (Coord.). Vigor de sementes: conceitos e testes. Londrina: Abrates, 1999. cap.4, p.1-26. 